\title{
Modeling the Growth of Forage Legumes
}

\author{
Brunna R. Rezende ${ }^{1}$, Michelane S. S. Lima ${ }^{1}$, Hygor A. Santana ${ }^{2}$, Wilhan V. dos Santos ${ }^{2} \&$ Anderson R. da Silva $^{2}$ \\ ${ }^{1}$ School of Agriculture, São Paulo State University, Botucatu, Brazil \\ ${ }^{2}$ Statistics and Geoprocessing Lab., Goiano Federal Institute, Urutaí, Brazil \\ Correspondence: Anderson R. da Silva, Statistics and Geoprocessing Lab., Goiano Federal Institute (IFGoiano), \\ Urutai, GO, Brazil. Tel: 55-64-3465-1975. E-mail: anderson.silva@ifgoiano.edu.br
}

Received: March 2, 2020

Accepted: April 3, 2020

Online Published: April 15, 2020

doi:10.5539/jas.v12n5p139

URL: https://doi.org/10.5539/jas.v12n5p139

\begin{abstract}
Modeling the growth curve of agricultural crops is of paramount importance so that management tasks such as fertilization and irrigation can be carried out at the appropriate time, increasing the vegetal yield. With this purpose, nonlinear models are commonly employed. The objective of this work was to fit some of the main nonlinear models that best describe the growth curve of some of the main species of forage legumes, namely: Crotalaria juncea, Canavalia ensiformis, Cajanus cajan and Dolichos lablab L. A randomized block experiment was conducted in field conditions between November 2015 and February 2016 in southeastern Goiás, Brazil. The variables plant height, stem diameter, fresh and dry mass were measured after 15, 30, 45, 60 and 90 days from sowing. The following models were fitted: Gompertz, Logistic, Brody and von Bertalanffy. The following goodness-of-fit criteria were calculated: $\mathrm{R}^{2}$ (normal and adjusted), AIC (Akaike Information Criterion) and absolute mean error. The growth curves of morphological variables are easier to model than the biomass curves. The von Bertalanffy and Gompertz models presented in general the best fit. The species C. juncea has an expressive biomass accumulation rate.
\end{abstract}

Keywords: fabaceae, Gompertz equation, growth curve, von Bertalanffy equation

\section{Introduction}

Forage legumes species have several uses, as human and animal food source and source of fertility for enrichment of soil. For the latter, they serve as nitrogen fixers contributing to soil fertility. They are relevant to pasture yield, making atmospheric $\mathrm{N}$ available to the soil-plant system, reducing expenses with nitrogen fertilization and improving the herd's food. Legume species produce large amounts of dry matter and have a high concentration of nutrients in the aerial part, have a deep and branched root system and are easily decomposed (Giacomini et al., 2003; Erasmo et al., 2004; Perin et al., 2007). The use of legumes is also a recommended practice for recovering degraded areas, as they protect the soil from erosion. Herbaceous and tree legumes may also be used in cropping systems to reduce soil erosion while also providing other products and services. They have the potential to contribute to soil erosion control because they have fast growth rates, high biomass production and some of them are drought-tolerant (Kaspar, Singer, Hatfield, \& Sauer, 2011). Including sole crops of herbaceous species such as Mucuna, or tree hedgerows with mixtures of maize and grain legumes has the potential to reduce runoff and soil erosion in smallholder farming (Muoni et al., 2019).

To carry out managements such as fertilization and irrigation in the appropriate timing and to identify possible problems in the development of crops, a specific study of the growth phase is recommended. Plant growth dynamics can be described by means of mathematical formulas, making it possible to evaluate some parts of the plant in the final growth, taking the advantage of obtaining information at regular intervals without the need for sophisticated equipment, once the information for these analyzes is, in general, the mass of the dry matter and the size of the photosynthesizing apparatus. Nonlinear regression models are usually indicated. The nonlinear regression analysis has economic advantages in agriculture because it allows knowing the speed at which production increment occurs. Therefore, the most relevant models for measuring biological growth have been the function Brody, Von Bertalanffy, Gompertez, logistical, Weibull, as cited by Koya and Goshu (2013). However, Parks (1982) shows that simulation studies indicate that growth functions may adjust incorrectly because they are flexible, thus recommending care when selecting models. 
In relation to linear models, the nonlinear models have some advantages such as the origin of the theory and biological, physical and chemical principles, being generally more parsimonious, that is, requiring a smaller number of parameters to give satisfactory modeling (Miguez, Archontoulis, \& Dokoohaki, 2018). However, there are disadvantages: the parameter estimation process requires iterative searching algorithms (e.g., Gauss-Newton, Golub-Pereyra) and the use of initial estimates for the parameters; they allow only approximations rather than exact inferences; they require a solid understanding of the phenomenon under study (Schabenberger \& Pierce, 2002).

Nonlinear models have been used in studies whose objective is to describe the growth curve and the accumulation of biomass of crops such as garlic (Reis et al., 2014), coffee (Fernandes, Pereira, Muniz, \& Savian, 2014), banana (Maia, Siqueira, Silva, Peternelli, \& Salomão, 2009) and onion (Pôrto, Cecílio-Filho, May, \& Barbosa, 2006). However, none involving the legumes under study. In this sense, the objective of this work was to fit and to identify, among some of the main nonlinear models, those that best describe the growth of some of the main species of forage legumes.

\section{Method}

\subsection{Field Experiment}

The study was conducted from November 2015 to February 2016, in an experimental area at southeastern, Goiás, Brazil, at the geographical coordinates: $17^{\circ} 29^{\prime} 23^{\prime \prime}$ South and $48^{\circ} 13^{\prime} 02^{\prime \prime}$ West, with average altitude of $807 \mathrm{~m}$.

A randomized complete block experiment with four replications was installed. Four species of forage legumes were sown in lines spaced $0.5 \mathrm{~m}$, constituting plots of dimension $3 \times 5 \mathrm{~m}$. Species: Crotalaria juncea cv. IAC-KR1, Canavalia ensiformis, Cajanus cajan cv. IAPAR 43-Aratã and Dolichos lablab cv. Rongai. From selecting three plants in each plot, the following variables were measured: stem diameter or primary branch $(\mathrm{cm})$, plant height $(\mathrm{cm})$, dry mass $(\mathrm{g})$ and fresh mass $(\mathrm{g})$, in six periods: 15, 30, 45, 60, 75 and 90 days after sowing. The dry mass was obtained after drying the biomass in an oven at $110{ }^{\circ} \mathrm{C}$ for 24 hours.

\subsection{Data Analysis and Modeling}

Data were submitted to repeated measures analysis of variance. The least squares means were then estimated for each period. Afterwards, the growth models in Table 1 were fitted.

Table 1. Nonlinear regression models for growth curves

\begin{tabular}{lll}
\hline Model & Function & Eq. \\
\hline Gompertz & $y i=\beta_{1} \mathrm{e}^{-\beta_{2} \exp \left(-\beta_{3} x i\right)}+\varepsilon_{i}$ & $(1)$ \\
Logistic & $y i=\beta_{1}\left(1+\beta_{2} \mathrm{e}^{-\beta_{3} x i}\right)^{-1}+\varepsilon_{i}$ & (2) \\
Brody & $y i=\beta_{1}\left(1-\beta_{2} \mathrm{e}^{-\beta_{3} x i}\right)+\varepsilon_{i}$ & $(3)$ \\
von Bertalanffy & $y i=\beta_{1}\left(1-\beta_{2} \mathrm{e}^{-\beta_{3} x i}\right)^{3}+\varepsilon_{i}$ & $(4)$ \\
\hline
\end{tabular}

Note. $\beta_{1}$ represents the maximum expected for the response, that is, the asymptote; $\beta_{2}$ does not present practical interpretation, being just a parameter of fitting; $\beta_{3}$ is related to the speed of growth; $x_{i}$ represents the $i$-th time; $y_{i}$ is the value of the response variable (least squares mean) in time $x_{i}$, and $\varepsilon$ represents the random error.

In order to select the best model, the following goodness-of-fit criteria (Table 2) were used: multiple coefficient of determination $\left(\mathrm{R}^{2}\right)$, adjusted multiple coefficient of determination $\left(\mathrm{R}_{\text {aj. }}{ }\right.$ ), Akaike's Information Criterion (AIC) and the Absolute Mean Error (AME). 
Table 2. Goodness-of-fit criteria for nonlinear regression models

\begin{tabular}{lll}
\hline Criterion & Function & Eq. \\
\hline Coefficient of determination & $\mathrm{R}^{2}=1-\frac{S Q R}{S Q T}$ & (1) \\
Adjusted coefficient of determination & $\mathrm{R}^{2}{ }_{\mathrm{aj}}=\frac{\mathrm{R}^{2}(n-1)-p}{n-p-1}$ & (2) \\
Akaike Information Criterion & $\mathrm{AIC}=2[p-\log L(\hat{\theta})]$ & (3) \\
Absolute Mean Error & $\mathrm{AME}=\frac{\sum_{i=1}^{n}|y i-\hat{y} i|}{n}$
\end{tabular}

Note. $S Q R=$ the residual sum of the squares; $S Q T=$ the total sum of squares. The higher the coefficient of determination, the better the fit of the model; $p$ is the number of model parameters and $L(\hat{\theta})$ is the maximum of the likelihood function; The lower the $A I C$, the better the adjustment.

The coefficient of determination $\left(\mathrm{R}^{2}\right)$ represents the proportion of the variation of the response variable that is explained by the variation of the predictor variable (the time in this case). The AIC (Akaike, 1974) is a value for comparing the goodness-of-fit of models based on the maximum of the likelihood function, which is dependent on the number of observations $(n)$ and parameters $(p)$ of the model, as well as the adjusted coefficient of determination.

All analyzes were performed with software R version 3.2.4 (www.R-project.org). For fitting models, the package 'easynls' was used. The iterative algorithm used for obtaining least squares estimates was Gauss-Newton, limited to 6.000 iterations.

\section{Results and Discussion}

According to Bassanezi (2002), the mathematical model is the interpretation of something real, used to understand natural phenomena and the way in which changes are made to it. The model chosen is based on the nature of the phenomenon, so it is necessary to study the model that best suits each species under study and the parameters observed.

Goodness-of-fit indicators of the models for each variable in each species are presented in Table 3, highlighting in bold those that indicate the highest degree of adjustment. In general, for morphological variables (height and diameter of the primary branch), there was more convergence, that is, those variables allowed easier fitting, excepting for the Brody model, which converged only for $C$. juncea and D. lablab height. Similar results were found by Reis et al. (2014), identifying that the Gompertz and Logistic models converged for all morphological and production variables of garlic. The Brody model only converged for one variable, dry mass.

The adjusted coefficient of determination $\left(\mathrm{R}^{2}{ }_{\mathrm{aj}}\right)$ for aerial fresh and dry matter weight were above 0.93 for all four species. Batista et al. (2013) achieved in their work a good performance in the adjustment of the Gompertz and Logistic models for Saccharum officinarum. The values of $\mathrm{R}_{\text {aj. }}^{2}$ were higher than 0.92 . They argue that these values signal that the models have been able to account for most of the fresh mass accumulation.

The values of coefficient of determination were above 0.94 in all combinations of variables and species. Reis et al. (2014) and Puiatti et al. (2013) observed that this is a common feature in nonlinear models, as they are built sppecifically to describe the biological phenomena. Thus, Oliveira et al. (2000) highlight the importance of using other adjustment criterion.

It was observed that the four criteria are concordant with each other, except for little variations for dry matter and stem diameter of $C$. ensiformis and D. lablab, respectively. In summary, the choice of the model was based on the largest number of indicators in agreement with each other. 
Table 3. Goodness-of-fit of nonlinear models for morpho-agronomic variables of $C$. juncea (CJ), C. ensiformis (CE), C. cajan (CC) and D. lablab (DL), according to the following criteria: AIC (Akaike's information criterion), AME (mean absolute error), $\mathrm{R}^{2}$ (coefficient of determination) and $\mathrm{R}_{\text {aj. }}^{2}$ (adjusted coefficient of determination)

\begin{tabular}{|c|c|c|c|c|c|c|c|c|c|c|c|c|c|c|c|c|c|}
\hline \multirow{2}{*}{ Crop } & \multirow{2}{*}{ Model } & \multicolumn{4}{|c|}{ Height } & \multicolumn{4}{|c|}{ Stem diameter } & \multicolumn{4}{|c|}{ Fresh matter } & \multicolumn{4}{|c|}{ Dry matter } \\
\hline & & $\mathrm{AIC}$ & AME & $\mathrm{R}^{2}$ & $\mathrm{R}_{\mathrm{aj}}^{2}$ & AIC & AME & $\mathrm{R}^{2}$ & $\mathrm{R}_{\mathrm{aj}}^{2}$ & $\mathrm{AIC}$ & AME & $\mathrm{R}^{2}$ & $\mathrm{R}_{\text {aj }}^{2}$ & AIC & AME & $\mathrm{R}^{2}$ & $\mathrm{R}_{\mathrm{aj}}^{2}$ \\
\hline \multirow{4}{*}{ CJ } & Gompertz & 42.75 & 3.67 & 0.9973 & 0.9955 & 13.51 & 0.36 & 0.9958 & 0.9930 & 51.96 & 8.49 & 0.9981 & 0.9968 & 54.11 & 8.60 & 0.9770 & 0.9616 \\
\hline & Logístico & 43.48 & 4.03 & 0.9969 & 0.9949 & 15.94 & 0.39 & 0.9937 & 0.9895 & 33.79 & 1.69 & 0.9999 & 0.9998 & 55.71 & 10.58 & 0.9699 & 0.9498 \\
\hline & Brody & 55.84 & 11.49 & 0.9761 & 0.9601 & NA & NA & NA & NA & NA & NA & NA & NA & NA & NA & NA & NA \\
\hline & von Bertalanffy & 46.10 & 4.59 & 0.9953 & 0.9921 & 15.00 & 0.39 & 0.9946 & 0.9911 & 64.85 & 22.95 & 0.9834 & 0.9723 & 53.50 & 8.53 & 0.9792 & 0.9653 \\
\hline \multirow{4}{*}{$\mathrm{CE}$} & Gompertz & 46.61 & 5.70 & 0.9836 & 0.9727 & 17.81 & 0.4298 & 0.9711 & 0.9518 & 57.89 & 14.12 & 0.9936 & 0.9894 & 52.69 & 7.55 & 0.9621 & 0.9369 \\
\hline & Logístico & 48.88 & 6.35 & 0.9761 & 0.9601 & 18.50 & 0.46 & 0.9676 & 0.9459 & 60.37 & 16.63 & 0.9904 & 0.9840 & 53.56 & 8.67 & 0.9562 & 0.9270 \\
\hline & Brody & NA & NA & NA & NA & NA & NA & NA & NA & NA & NA & NA & NA & NA & NA & NA & NA \\
\hline & von Bertalanffy & 45.95 & 5.41 & 0.9853 & 0.9755 & 17.63 & 0.4205 & 0.9719 & 0.9532 & 64.13 & 20.71 & 0.9820 & 0.9701 & 52.38 & 7.68 & 0.9640 & 0.9400 \\
\hline \multirow{4}{*}{$\mathrm{CC}$} & Gompertz & 53.13 & 9.21 & 0.9719 & 0.9532 & 17.41 & 0.48 & 0.9840 & 0.9734 & 42.61 & 3.36 & 0.9978 & 0.9963 & 41.55 & 2.98 & 0.9829 & 0.9714 \\
\hline & Logístico & 54.94 & 11.37 & 0.9620 & 0.9367 & 19.06 & 0.5333 & 0.9790 & 0.9650 & 47.24 & 5.16 & 0.9952 & 0.9920 & 42.20 & 3.23 & 0.9809 & 0.9682 \\
\hline & Brody & NA & NA & NA & NA & NA & NA & NA & NA & NA & NA & NA & NA & NA & NA & NA & NA \\
\hline & von Bertalanffy & 52.49 & 8.46 & 0.9748 & 0.9579 & 16.57 & 0.4541 & 0.9861 & 0.9769 & 41.82 & 3.26 & 0.9981 & 0.9968 & 41.18 & 2.80 & 0.9839 & 0.9731 \\
\hline \multirow{4}{*}{ DL } & Gompertz & 49.72 & 7.46 & 0.9845 & 0.9741 & 12.79 & 0.27 & 0.9837 & 0.9728 & 55.77 & 11.63 & 0.9950 & 0.9916 & 36.90 & 2.42 & 0.9942 & 0.9903 \\
\hline & Logístico & 53.51 & 9.44 & 0.9708 & 0.9514 & 11.63 & 0.28 & 0.9866 & 0.9776 & 43.04 & 4.13 & 0.9994 & 0.9990 & 41.50 & 3.07 & 0.9874 & 0.9791 \\
\hline & Brody & 57.65 & 12.37 & 0.9419 & 0.9031 & NA & NA & NA & NA & NA & NA & NA & NA & NA & NA & NA & NA \\
\hline & von Bertalanffy & 49.30 & 6.71 & 0.9855 & 0.9759 & 13.43 & 0.29 & 0.9818 & 0.9697 & 64.81 & 23.31 & 0.9773 & 0.9622 & 42.17 & 3.31 & 0.9860 & 0.9766 \\
\hline
\end{tabular}

The models that most stood out regarding the degree of adjustment were: von Bertalanffy and Gompertz, with the best adjustment in about 56\% (9) and 25\% (4) of the scenarios (species $\times$ variables), respectively. In the works of Reis et al. (2014), Puiatti et al. (2013), and Maia, Siqueira, Silva, Peternelli, and Salomão (2009), the logistic model presented the best adjustment for growth curves.

Figure 1 shows the fitted models that best describe the growth curves of each species for each variable. It is observed that the $C$. juncea is the crop that, although with medium height (Figure 1A), presents the greatest accumulation and the highest rate of accumulation of mass (Figures $1 \mathrm{C}$ and 1D), followed by C. ensiformis. This is explained by the significant increase in the diameter of the primary branch between 40 and 70 days after sowing (Figure 1B).

For plant height, the von Bertalanffy model was adjusted for all crops, although the Gompertz model presented a slightly better adjustment for $C$. juncea (Figure 1A). Considering the diameter of the primary branch, the Gompertz model presented the best overall adjustment (Figure 1B).

There was greater variation regarding the model for fresh matter, namely logistic for C. juncea and D. lablab, Gompertz for $C$. ensiformis and von Bertalanffy for $C$. cajan. For dry matter, the von Bertalanffy model was adjusted for all crops, except for the D. lablab.

Fernandes, Pereira, Muniz, and Savian (2014) obtained a good fit of Gompertz and logistic models for describing increments in fresh mass of coffee. Confalone et al. (2010) used the expolinear model to evaluate soybean growth due to different levels of water deficit. The model adjusted satisfactorily for soybean growth variation.

The models were able to describe the accumulation of fresh mass of the legumes under study, it is possible to verify that the maximum accumulation was reached at 85 days, being acquired as time increases (Figure 1C), however, there was greater variation regarding the models, being logistical for $C$. juncea and D. lablab, Gompertz for $C$. ensiformis and von Bertalanffy for $C$. cajan. Fernandes et al. (2014) obtained for coffee fresh matter growth curve a good fit with the Gompertz and Logistics models. For dry matter, the von Bertalanffy model was adjusted for all species, except for the D. lablab. 

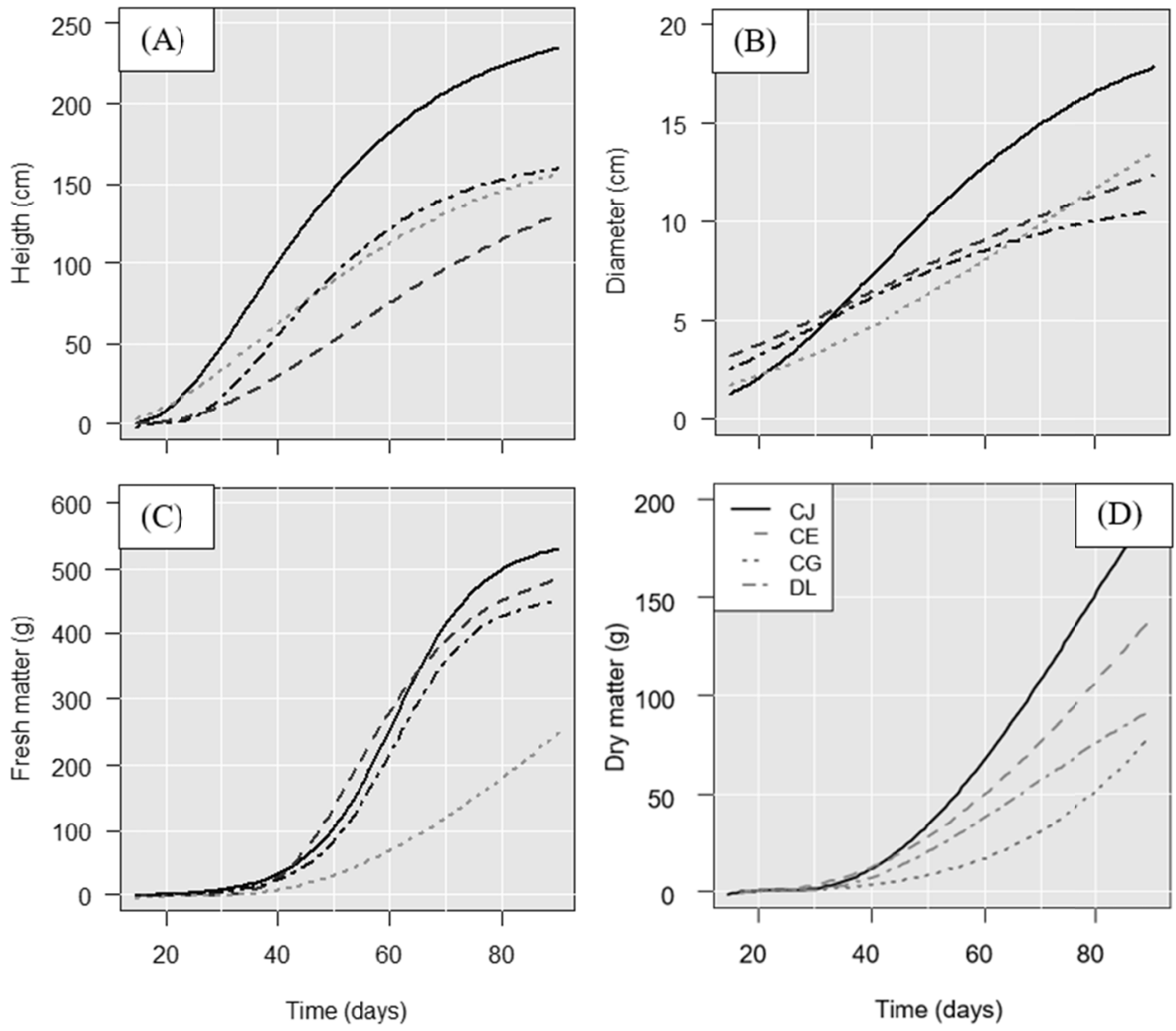

Figure 1. Fitted models for growth of C. juncea (CJ), C. ensiformis (CE), C. cajan (CC), D. lablab (DL), for: (A) plant height, (B) diameter of the primary branch, (C) aerial fresh matter weight and (D) aerial dry matter weight

\section{Conclusions}

The models von Bertalanffy and Gompertz presented, in general, the highest goodness-of-fit for morphological and biomass growth of forage legumes.

The species $C$. juncea presented the highest biomass accumulation rate.

The adjustment of models in study proved to be promising to analyze the growth curve of morphological variables. However, it is understood that further studies are necessary, considering that results with the proposed objective are scarce in the literature.

\section{Acknowledgments}

To the Goiano Federal Institute (process number 23219.000362.2020-01) for the financial support and to the Agroecology Research Group (NEPA, IF Goiano) for supplying the seeds.

\section{References}

Akaike, H. A. (1974). New Look at the Statistical Model Identification. IEEE Transactions on Automatic Control, 19(6), 716-723. https://doi.org/10.1109/TAC.1974.1100705

Bassanezi, R. C. (2002). Ensino-aprendizagem com Modelagem Matemática. São Paulo: Contexto.

Batista, E. L. S., Zolnier, S., Ribeiro, A., Lyra, G. B., Silva, T. G. F., \& Boehringer, D. (2013). Modeling of growth of sugarcane cultivars during the crop formation period. Revista Brasileira de Engenharia Agrícola e Ambiental, 17(10), 1080-1087. https://doi.org/10.1590/S1415-43662013001000009

Confalone, A. E., Bernardes, M. S., Costa, L. C., Righi, C. A., Neto, D. D. Martin, T. N., ... Pereira, C. R. (2010). Expolinear model on soybean growth in Argentina and Brazil. Ciência Rural, 40(5), 1009-1016. https://doi.org/10.1590/S0103-84782010000500002

Erasmo, E. A. L., Azevedo, W. R., Sarmento, R. A., Cunha, A. M., \& Garcia, S. L. R. (2004). Potential of species used as green manure in integrated weed management. Planta Daninha, 22(3), 337-342. 
Fernandes, T. J., Pereira, A. A., Muniz, J. Á., \& Savian, T. V. (2014). Selection of nonlinear models for the description of the growth curves of coffee fruit. Coffee Science, 9(2), 207-215. https://doi.org/10.25186/ cs.v9i2.618

Giacomini, S. J., Aita, C., Vendruscolo, E. R. O., Cubilla, M., Nicoloso, R. S., \& Fries, M. R. (2003). Dry matter, $\mathrm{C} / \mathrm{N}$ ratio and accumulation of nitrogen, phosphorus and potassium in mixtures of soil cover plants. Brazilian Journal of Soil Science, 27(2), 325-334. https://doi.org/10.1590/S0100-06832003000200012

Kaspar, T. C., Singer J. W., Hatfield J. L., \& Sauer T. J. (2011). The use of cover crops to manage soil. Soil Management: Building a Stable Base for Agriculture (pp. 321-337). Wiley Online Library. https://doi.org/ 10.2136/2011.soilmanagement.c21

Koya, P. R., \& Goshu, A. T. (2013). Generalized Mathematical Model for Biological Growths. Journal of Modelling and Simulation, 1, 42-53. https://doi.org/10.4236/ojmsi.2013.14008

Maia, E., Siqueira, D. L., Silva, F. F., Peternelli, L. A., \& Salomão, L. C. C., (2009). Method of comparison of models non-linear regression in bananas trees. Ciência Rural, 39(5), 1380-1386. https://doi.org/10.1590/ S0103-84782009000500012

Miguez, F., Archontoulis, S., \& Dokoohaki, H. (2018). Chapter 15: Nonlinear Regression Models and Applications. In B. Glaz, \& K. M. Yeater (Eds.), Applied Statistics in Agricultural, Biological, and Environmental Sciences (pp. 401-448). ASA, CSSA, and SSSA, Madison, WI. https://doi.org/10.2134/ appliedstatistics.2016.0003

Muoni, T., Koomson, E., Öborn, I., Marohn, C., Watson, C., Bergkvist, G., ... Duncan, A. (2019). Reducing soil erosion in smallholder farming systems in east Africa through the introduction of different crop types. Experimental Agriculture, 1-13. https://doi.org/10.1017/S0014479719000280

Oliveira, H. N., Lobo, R. B., \& Pereira, C. S. (2000). Comparison of non-linear models for describing growth of Guzerat beef cattle females. Pesquisa Agropecuária Brasileira, 35(9), 1843-1851. https://doi.org/10.1590/ S0100-204X2000000900017

Parks, J. R. (1982). A Theory of Feeding and Growth of Animals. Springer, Berlin-Heidelberg-New York. https://doi.org/10.1007/978-3-642-68330-5

Perin, A., Santos, R. H. S., Urquiaga, S., Guerra, J. G. M., \& Cecon, P. R. (2004). Production of phytomass, accumulation of nutrients and biological nitrogen fixation by green manure in isolated and intercropped cultivation. Pesquisa Agropecuária Brasileira, 39(1), 35-40. https://doi.org/10.1590/S0100-204X2004 000100005

Pôrto, D. R. Q., Cecilio-Filho, A. B., May, A., \& Barbosa, J. C. (2006). Macronutrients accumulation by onion 'Optima' established by direct sowing. Horticultura Brasileira, 24(4), 470-475. https://doi.org/10.1590/ S0102-05362006000400015

Puiatti, G. A., Cecon, P. R., Nascimento, M., Puiatti, M., Finger, F. L., Silva, A. R., \& Nascimento, A. C. C. (2013). Cluster analysis applied to nonlinear regression models selection for the description of dry matter accumulation of garlic plants. Revista Brasileira de Biometria, 31(3), 337-351. Retrieved from http://jaguar.fcav.unesp.br/RME/fasciculos/v31/v31_n3/A2_Guilherme_PauloCecon

Reis, R. M., Cecon, P. R., Puiatti, M., Finger, F. L., Nascimento, M., Silva, F. F., ... Silva, A. R. (2014). Nonlinear regression models applied to clusters of garlic accessions. Horticultura Brasileira, 32(2), 178-183. https://doi.org/10.1590/S0102-05362014000200010

Schabenberger, O., \& Pierce, F. J. (2001). Contemporary statistical models. CRC, Boca Raton. https://doi.org/ $10.1201 / 9781420040197$

\section{Copyrights}

Copyright for this article is retained by the author(s), with first publication rights granted to the journal.

This is an open-access article distributed under the terms and conditions of the Creative Commons Attribution license (http://creativecommons.org/licenses/by/4.0/). 